\title{
Azun Candina
}

Por una vida digna y decorosa: Clase media y empleados públicos en el siglo XX chileno. Esfera de Papel Libros, Facultad de Filosofía y Humanidades, Universidad de Chile, Santiago, 2009, 107 páginas. ISBN 978-956-817-015-8.

Azun Candina explora la construcción de la identidad de la clase media en Chile, especialmente de los empleados públicos. Desde una perspectiva socio-cultural, la clase media se define o autodefine como un grupo que no pertenece ni a las clases altas ni a las bajas de la sociedad chilena, pero que se siente perteneciente a un grupo. La autora, mediante un trabajo bien esquematizado y apoyado por fuentes orales, plantea que se pueden definir los parámetros que estos sujetos históricos utilizaron para pertenecer a este grupo social y desarrollar una conciencia de clase, la cual se manifestaba en una capacidad de ahorro e inversión, de creer que la educación y la profesión era el vehículo para el éxito así como también el mérito y la sobriedad. Esta identidad de clase media se manifiesta en una tensión a lo largo de la historia entre los símbolos culturales que utilizan para diferenciarse de las otras clases y las políticas cambiantes del gobierno de Chile durante el siglo XX, los esfuerzos para tener una mejor calidad de vida mediante reformas dentro del sistema y la pérdida de derechos durante la régimen militar y el retorno de la democracia.

La sociedad chilena se define como miembros de la clase media y en los discursos políticos se hacen llamados a reformas para esta clase. No obstante, en la historiografía nacional existen muy pocos trabajos sobre este sector de la sociedad. Esto se debe, a juicio de la autora, a que existe más interés por los otros miembros de la población, es más llamativo ver la resistencia y explotación de los grupos bajos o historia desde arriba. Su difícil definición y categorización es la que en parte contribuye a que no se realicen grandes estudios sobre el tema. Sin embargo, estos sí son parte de la memoria histórica, tal vez no formaron parte activa en luchas de los sectores populares, pero decidieron actuar y transformar el sistema desde dentro, pues consideraban que esta era el verdadero camino a la democracia.

La obra Por una vida digna y decorosa plantea explícitamente como hipótesis que los empleados fiscales generaron una identidad propia que los distinguía de los otros sectores de la sociedad, así como también los diferenciaba de otros trabajadores, y que fueron las reformas políticas que llevaron a cabo las que permitieron definir su rol social. Para poder apoyar lo anterior, Azun Candina señala como objetivo principal identificar cómo se construyó la identidad de la clase media y cómo los empleados públicos reivindicaron sus derechos y condiciones como trabajadores asalariados distintos de otros trabajadores.

Las ideas principales que se rescatan en esta obra están agrupadas en tres capítulos perfectamente definibles, pues la historiadora trata de explicar las preguntas que se plantea (algunas veces estas están explicitas y otras implícitas).

En el primer y segundo capítulo trata de recoger o de identificar en qué se caracteriza este grupo llamado "clase media", que no es ni aristócrata ni popular; para hacer esta caracterización hace una definición histórico-antropológica de este grupo social, donde entiende que tiene elementos en común como personas con traje, que posee un nivel de educación, que busca tener un cierto nivel de cultura, más cercano a la modernización urbana, arribismo, que se diferencia de la cultura popular, que trata de aparentar vivir en una calidad de vida lo más semejante a la clase alta, etc. 
La historiadora no solo entrega los resultados de su ensayo sino también el procedimiento teórico en el cual fundamenta su investigación. Mediante los trabajos de Roger Chartier, Peter Burke y Edward Tompson, la autora enfatiza que la identidad de la clase media es una construcción sociocultural más que socioeconómica, ya que este grupo social utiliza artefactos culturales como formas de representación y producción de una conciencia de clase. Para ella, la identidad de la clase media es el resultado de "la tensión permanente producida entre la necesidad de construir esos sistemas de relaciones y símbolos propios de la cultura sobre una base estable, y las características cambiantes de esos sistemas de relaciones en la vida real y cotidiana de los sujetos" (pág. 22). Si bien plantea una definición de clase media, señala que esta no permanece inmóvil, sino que va cambiando a través del contexto y de la evolución socioeconómica de una sociedad especifica, en cierto modo y apoyada en la historiografía; Candina propone que esta definición esta forjada en una especie de ideal, el "cómo debía ser".

Aunque simpatizaran con los dolores y penas del mundo obrero y aunque ellos sufrieran también las consecuencias de una situación económica estrecha, tendieron a diferenciarse de ellos precisamente a partir de esos necesarios sacrificios [...] Fue, en parte, una decisión consciente en la que empeñaron sus refuerzos y también una a la que llegaron empujados para salir de la miseria (pág. 39).

Una vez que explicado lo anterior, Candina se propone definir a los empleados públicos, en los cuales trata de diferenciar los altos cargos de la burocracia estatal baja y media; para ella estos últimos corresponden a personas

que poseen un promedio de entre 9 y 12 años de educación formal y que no ingresan a la administración pública directamente a cargos directivos, donde más del $90 \%$ tiene estudios superiores universitarios completos y reciben asignaciones especiales debido a sus labores directivas y a las profesiones que desempeñan... (pág. 25).

En el segundo capítulo la historiadora explica cómo a través de la demanda laboral la clase media, y sobre todo el empleado público, fue buscando medios para tener una vida digna mediante una conciencia de clase que se explica por la responsabilidad social, la conducta moral, la educación, etc., y empieza a distanciarse de los obreros o la pobreza. Estos trabajadores públicos se reúnen en organizaciones sociales gremiales como clubes deportivos o de cultura, pues no podían sindicalizarse; sin embargo, estas organizaciones de trabajadores luchaban colectivamente por sus derechos laborales y consecuentemente mejorar su calidad de vida. En este sentido, a juicio de la autora, fue este proceso el que le dio a los empleados públicos una conciencia como trabajadores asalariados y actores importantes dentro del engranaje de la sociedad:

El sueldo, los reajustes anuales y su aprobación por ley se convirtieron en el gran pilar de las luchas de los empleados públicos. Se entiende fácilmente el poder de esta convocatoria en un país asolado por la inflación creciente, que disminuirá radicalmente el poder adquisitivo: no hubo, en esas circunstancias, nada mas importante y urgente que defender lo conseguido y luchar por nuevos aumentos (pág. 59).

Si bien durante los gobiernos radicales la democracia cristiana y otros empezaron a gestar en Chile ( y en el resto de los países de América Latina) el movimiento del Estado de bienestar, los empleados públicos aprovecharon para implementar políticas más activas para ellos, como por ejemplo, que los empleados públicos se pudieran sindicalizar, u otras más sociales, 
como diferenciarse de los obreros industrializados que tenían mejores beneficios sindicales que los empleados públicos. Todo esto genera un conflicto o relación con los gobiernos de la época o con algunas posturas políticas como revolucionarios y posturas conservadoras.

La ANEF se autorreconoció así un rol que ya no podía ser desmentido ni minimizado por ningún parlamentario ni autoridad del gobierno, y desde allí se opuso a las iniciativas de crear agrupaciones y sindicatos paralelos, combatiendo los propios intentos internos de restarse a la unidad con el resto de los trabajadores (pág. 64).

El capítulo termina en como la ANEF o la agrupación nacional de empleados fiscales entrega su apoyo a la Unidad Popular, pero que tampoco los consideró en una política clara, pues no se les reconocía como proletarios. La autora recalca eso sí un punto importante y es que la forma de movilización de la ANEF era considerada como una lucha vanguardista por su forma de organización y su apego a los proyectos de democratización nacional.

El último capítulo de análisis habla sobre lo que ocurrió después de 1973, con el golpe militar. El proyecto de vida de los empleados basado en la carrera funcionaria como forma de ascenso social ya no existe, pues el neocapitalismo disminuyó el rol del Estado y fomentó la flexibilidad laboral y la iniciativa individual, así como la libre empresa. Esta situación afectó al concepto de identidad de los empleados públicos, pues estas medidas junto con la reforma del código laboral, borraron la distinción entre empleado público y obreros, así como también la desaparición de los logros sociales y económicos que habían obtenido en los gobiernos anteriores. El gobierno militar rompió la seguridad que ofrecía el mérito en el trabajo y entregó desprotección al futuro del empleado público con la aparición de las Isapres y las AFP. El capítulo finaliza con una importante proyección sobre el futuro de la clase media y el cambio generacional que provocó el neoliberalismo y la ruptura del empleado público con el Estado.

Dentro de la investigación llevada a cabo por la historiadora Azun Candina se puede destacar metodológicamente que su análisis está basado en la representación de la clase media y el empleado público a partir de los conceptos de cultura e identidad. Ella rescata no solo las fuentes oficiales escritas del periodo, sino también la literatura, la fotografía, la página de internet, entrevistas y un amplio espectro de bibliografía especializada que trata el tema de estudio, y además de rescatar una parte de la memoria contemporánea del sujeto histórico que no ha sido muy analizada. Si bien su obra corresponde a una investigación de tipo ensayístico deja claramente establecido sus postulados y las interrogantes que plantea para dejarlas sujetas a reflexión. Ella aclara que lo que propone no es un trabajo finalizado y que puede ser perfectamente cuestionable desde otro tipo de estudios. Otro asunto a mencionar es la fácil lectura que se puede hacer de esta investigación. Ofrece una introducción, un desarrollo y una conclusión, lo cual da una visión muy esquemática del problema a investigar; esto puede ser un arma de doble filo, pues si bien su estudio es para un público académico, también es para el público en general y cae en algunos momentos en elementos narrativos y en repetir mucho las ideas (en esta lógica de repetir ideas, utiliza las fuentes literarias o fotográficas para dejar claro lo que explica).

Lo novedoso de este estudio es que permite al lector sumergirse en el imaginario de la conciencia de clase media, permite mediante su lenguaje fácil sentirse identificado. También es interesante cómo la autora humanamente explica qué la motivó a realizar su trabajo. Otro punto interesante es cómo utiliza elementos de la nueva historia cultural, algo no muy desarrollado en Chile y lo combina perfectamente con la historia social, quitándole ese 
marcado rango socio-económico. Sin embargo, la obra no muestra como esta "conciencia de la clase media" entra en conflicto con otras clases sociales; solo hay menciones pero no profundizadas. Tal vez lo repetitivo en su trabajo historiográfico es que observa la política cómo cambió esta conciencia de clase. Creo que faltaron elementos para comprender mejor esta conciencia, la cual no solo se expresó en ámbitos político-económico-sociales, La autora trata de seguir la línea socio cultural de la historia al final termina la vía más a lo social y produce un quiebre con los primeros capítulos que son análisis más culturales del tema de estudio.

Para finalizar, la obra por una vida digna y decorosa... posee una importancia historiográfica importante al poner en el tapete un sector de la sociedad que no ha sido trabajado en profundidad por los historiadores chilenos. La temática de la clase social y sobre todo la ruptura provocada por el régimen militar es una propuesta novedosa ya que puede entregar elementos clave para entender el cambio de mentalidad entre los 70 y 90 de los trabajadores más experimentados que tienen la visión de ascender mediante el mérito comparado con los empleados jóvenes que tienen la postura de que las oportunidades son las que permiten el ascenso social.

Cristián Gerardo Guzmán Suazo Universidad de Concepción 